\title{
PERANCANGAN ROBOT PENDETEKSI LINGKUNGAN BERBAHAYA BERBASIS LOGIKA FUZZY DAN KONTROL ANDROID
}

\section{ROBOT DESIGN OF HAZARDOUS ENVIRONMENT DETECTION BASED ON FUZZY LOGIC AND ANDROID CONTROL}

\author{
Atik Novianti, S.ST., M.T. ${ }^{1}$, Unang Sunarya, S.T., M.T. ${ }^{2}$ \\ ${ }^{1,2}$ Fakultas Ilmu Terapan, Telkom University, Bandung \\ ${ }^{1}$ atiknovianti@ telkomuniversity.ac.id, ${ }^{2}$ unangsunarya@ elkomuniversity.ac.id
}

\begin{abstract}
Abstrak
Gas merupakan unsur penting di lingkungan, yang dapat menjadi salah satu parameter untuk menentukan kondisi lingkungan bersih atau tercemar. Sifat gas yang transparan menyebabkan sulit untuk mengetahui kondisi lingkungan tersebut, apakah masih bersih atau sudah tercemar gas berbahaya. Pada penelitian ini dibuat suatu robot kontrol jarak jauh yang dilengkapi dengan dua sensor gas karbon monoksida dan ammonia. Pengendalian robot tersebut berbasis mikrokontroler ATmega32 dan diakses menggunakan tablet Android dengan media bluetooth sebagai interface. Metode logika fuzzy Sugeno digunakan untuk memutuskan hasil pembacaan sensor pada robot, apakah kondisi lingkungan aman atau berbahaya. Berdasarkan hasil pengujian didapatkan bahwa arah pergerakan robot sudah sesuai $100 \%$, jarak jangkau maksimum bluetooth pada kondisi NLOS (Non Line of Sight) adalah 27 meter, dan keputusan fuzzy sudah bekerja sesuai yang diharapkan.
\end{abstract}

Kata kunci : robot, karbon monoksida, amonia, fuzzy Sugeno, NLOS

\begin{abstract}
Gas is an important element in environment, which can be one of the parameters to determine the environmental conditions are clean or polluted. Transparent gas properties make it difficult to determine the environmental conditions, whether they are clean or have been contaminated with hazardous gases. In this study created a remote control robot is equipped with two gas sensor carbon monoxide and ammonia. The robot control based on ATmega32 microcontroller and accessed using the Android tablet with bluetooth as media interface. Sugeno fuzzy logic method is used to determine the reading sensors on the robot, whether safe or hazardous environmental conditions. Based on the test results showed that the direction of movement of the robot is in conformity 100\%, the maximum range of bluetooth in NLOS (Non Line of Sight) is 27 meters, and a fuzzy decision already working as expected.
\end{abstract}

Keywords : robot, carbon monoxide, ammonia, Sugeno fuzzy, NLOS

\section{PENDAHULUAN}

Salah satu unsur penting di lingkungan yang dapat menjadi parameter untuk menentukan kondisi lingkungan bersih atau tercemar adalah gas. Sifat gas yang transparan menyebabkan sulit untuk mengetahui kondisi lingkungan tersebut, apakah masih bersih atau sudah tercemar gas berbahaya. Karbon monoksida merupakan salah satu jenis gas yang berbahaya. Sifat dari karbon 
monoksida (CO) antara lain tidak berwarna, tidak berbau, dan dihasilkan dari pembakaran tidak sempurna material yang mengandung zat arang atau bahan organik [1]. Efek gas karbon monoksida untuk kadar 50 ppm masih tergolong aman, sedangkan lebih dari itu mulai menimbulkan efek yang berbahaya bagi tubuh [1]. Selain gas karbon monoksida, juga terdapat gas berbahaya lain yaitu gas ammonia yang pada ambang lebih dari $25 \mathrm{ppm}$ dapat berbahaya bagi tubuh [2]. Pada penelitian ini digunakan metode logika fuzzy untuk mengklasifikasi apakah lingkungan tersebut aman atau bahaya dari gas, dimana kedua sensor karbon monoksida dan amonia ditanam dalam robot sehingga dapat secara dinamis digerakan dengan kontrol aplikasi Android. Penelitian lain terkait robot kontrol Android adalah "Rancang Bangun Robot Beroda Berbasis Android Menggunakan Komunikasi USB" [3]. Penelitian [3] hanya terpaku pada proses kontrol pergerakan arah robot, belum ada penggunakan aplikasi pembacaan sensor yang diolah dengan logika fuzzy.

\section{LOGIKA FUZZY}

Logika fuzzy pertama kali diperkenalkan oleh Lotfi A. Zadeh [4]. Logika tersebut memiliki derajat keanggotaan dalam rentang 0 (nol) hingga 1 (satu), berbeda dengan logika digital yang hanya memiliki dua nilai yaitu 0 (nol) atau 1 (satu). Logika fuzzy digunakan untuk menerjemahkan suatu besaran yang diekspresikan menggunakan bahasa (linguistic), misalkan besaran laju kendaraan yang diekspresikan dengan pelan, agak cepat, cepat, dan sangat cepat. Secara umum dalam sistem logika fuzzy terdapat empat buah elemen dasar, yaitu [5] :

1. Basis kaidah (rule base), yang berisi aturan-aturan secara linguistik yang bersumber dari para pakar;

2. Suatu mekanisme pengambilan keputusan (inference engine), yang memperagakan bagaimana para pakar mengambil suatu keputusan dengan menerapkan pengetahuan (knowledge);

3. Proses fuzzifikasi (fuzzyfication), yang mengubah besaran tegas (crisp) ke besaran fuzzy;

4. Proses defuzzifikasi (defuzzyfication), yang mengubah besaran fuzzy hasil dari inference engine menjadi besaran tegas (crisp).

\section{DESAIN SISTEM}

\subsection{Diagram Blok Sistem}

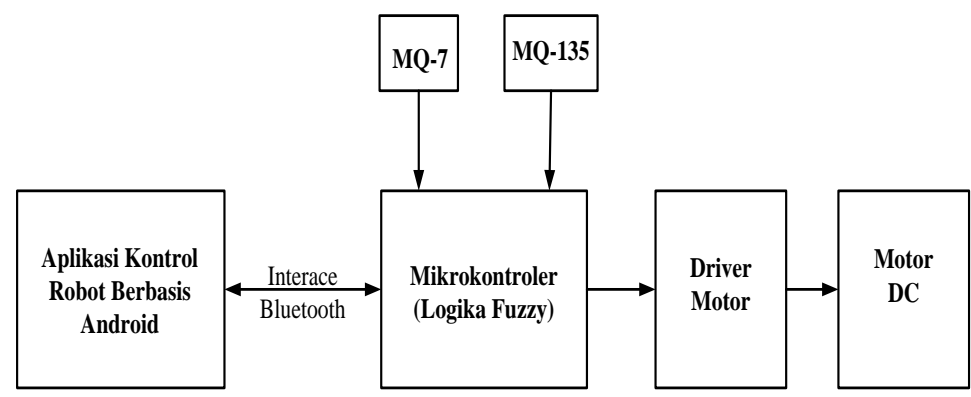

Gambar 1. Diagram Blok Sistem Robot Kontrol

Perancangan ini menggunakan modul bluetooth HC-06 pada sisi perangkat keras mikrokontroler ATmega32, sedangkan di sisi lain menggunakan modul bluetooth yang tertanam pada laptop. Konfigurasi bluetooth HC-06 menggunakan ATCommand. Bluetooth diset pada baud rate 9600 bps, disesuaikan dengan baud rate serial yang digunakan pada mikrokontroler [6]. Pada 
pengembangan aplikasi robot ini digunakan mikrokontroler ATmega32 sebagai otak yang mengatur kerja komponen lainnya seperti arah pergerakan robot dengan motor DC melalui driver motor L298. Selain itu melakukan pembacaan sensor gas sebagai masukan logika fuzzy yang hasilnya dikirimkan kembali ke aplikasi Android untuk ditampilkan.

\subsection{Diagram Alir Sistem}

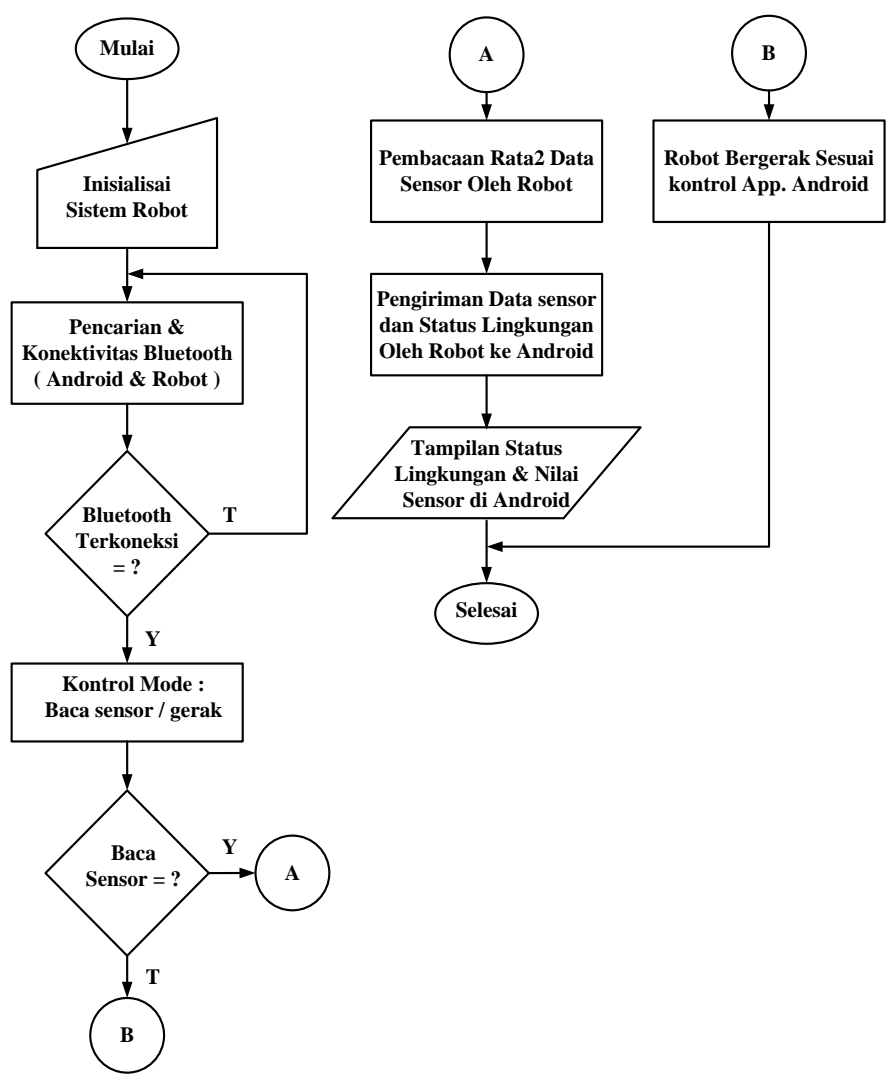

Gambar 2. Diagram Alir Sistem Robot Kontrol

\subsection{Perancangan Robot}

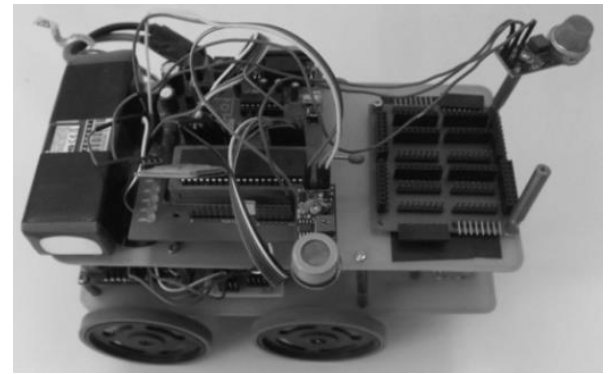

Gambar 3. Desain Robot Kontrol

\subsection{Konfigurasi Bluetooth}

Sebelum digunakan, bluetooth HC-06 harus dikonfigurasi terlebih dahulu agar sesuai dengan protokol bluetooth yang akan diajak berkomunikasi. Konfigurasi ini menggunakan perangkat lunak Hterm [7]. 


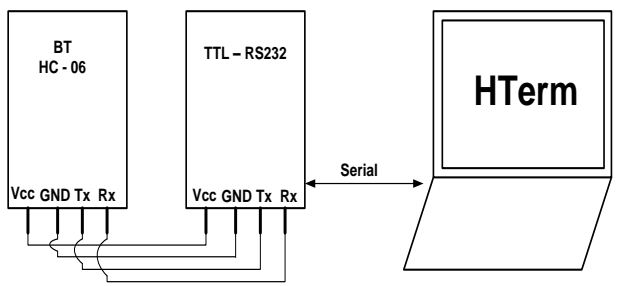

Gambar 4. Konfigurasi Bluetooth HC-06

Tabel 1. Konfigurasi Bluetooth HC-06 ATCommand

\begin{tabular}{|c|l|c|}
\hline No. & \multicolumn{1}{|c|}{ Perintah } & Respon \\
\hline 1 & AT & OK \\
\hline 2 & AT+NAMEusa & OKsetname \\
\hline 3 & AT+BAUD4 & OK9600 \\
\hline 4 & AT+PIN2040 & OKsetPIN \\
\hline
\end{tabular}

\subsection{Perancangan Logika Fuzzy}

Derajat keanggotaan gas karbon monoksida MQ-7 :

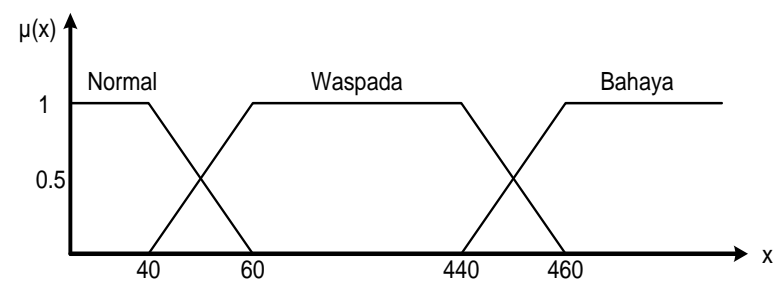

Gambar 5. Derajat Keanggotaan Masukan Karbon Monoksida

Derajat keanggotaan harmful gas amonia MQ-135 :

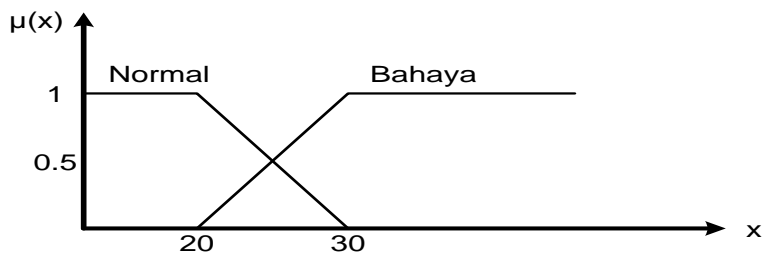

Gambar 6. Derajat Keanggotaan Masukan Amonia

Aturan fuzzy yang digunakan :

Tabel 2. Aturan Fuzzy untuk Sensor Gas

\begin{tabular}{|c|c|c|c|}
\hline amonia & Normal & Waspada & Bahaya \\
\hline Normal & aman & waspada & bahaya \\
\hline Bahaya & bahaya & bahaya & bahaya \\
\hline
\end{tabular}


Derajat keanggotaan keluaran sistem fuzzy:

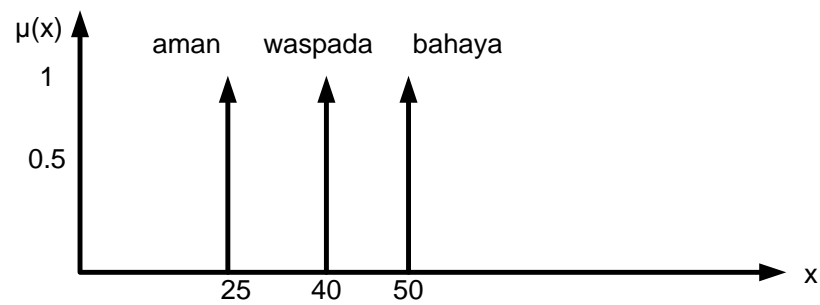

Gambar 7. Derajat Keanggotaan Keluaran Sistem

\subsection{Perancangan Perangkat Lunak Aplikasi Android}

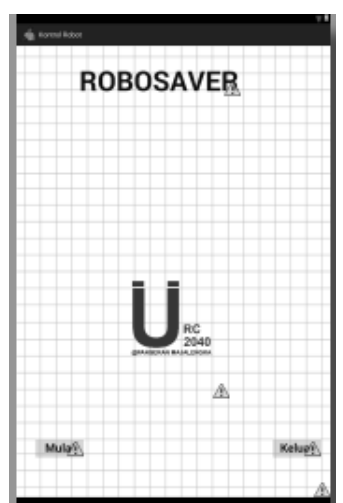

Halaman Pertama

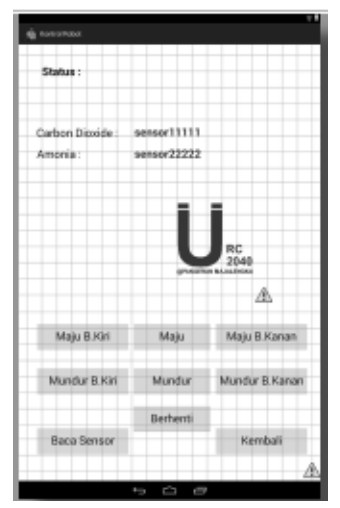

Halaman Kedua

Gambar 8. Desain Lingkungan Kontrol Android

Perangkat lunak untuk mengakses pengendalian robot menggunakan sistem operasi Android yang berbasis Linux. Sistem operasi ini menyediakan platform terbuka bagi para pengembang untuk menciptakan aplikasi mereka sendiri, yang dapat digunakan oleh bermacam peranti bergerak. Terdapat dua jenis distributor sistem operasi Android, yakni yang mendapat dukungan penuh dari Google atau Google Mail Service (GMS), dan yang benar-benar bebas distribusinya tanpa dukungan langsung Google atau dikenal sebagai Open Handset Distribution (OHD) [8].

\subsection{Modul Sensor Gas Karbon Monoksida MQ-7}

Modul MQ-7 memiliki range pembacaan nilai antara 20 hingga 2000 ppm [9], oleh sebab itu perlu dilakukan kalibrasi sesuai dengan spesifikasi data sensor MQ-7 pada buku manualnya.

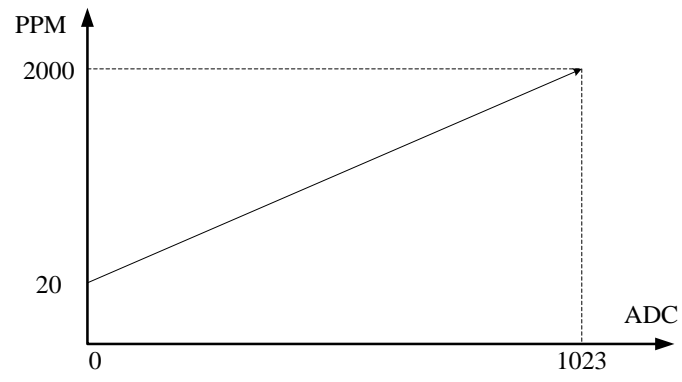

Gambar 9. Kalibrasi Modul MQ-7 
Persamaan yang menunjukkan korelasi antara PPM dan ADC adalah sebagai berikut :

$$
P P M=(1.9355 \times A D C)+20
$$

PPM merupakan nilai gas hasil pembacaan dalam satuan part permilion (ppm), sedangkan ADC merupakan nilai pembacaan feature analog to digital modul yang tertanam pada mikrokontroler. Nilai ADC yang digunakan adalah 10 bit dengan resolusi 1024 (0 sampai 1023).

\subsection{Modul Sensor Gas Berbahaya (amonia, benze, hydrogen) MQ-135}

Modul MQ-135 memiliki range pembacaan nilai antara 10 hingga 1000 ppm [10], oleh sebab itu perlu dilakukan kalibrasi sesuai dengan spesifikasi data sensor MQ-135 pada buku manualnya.

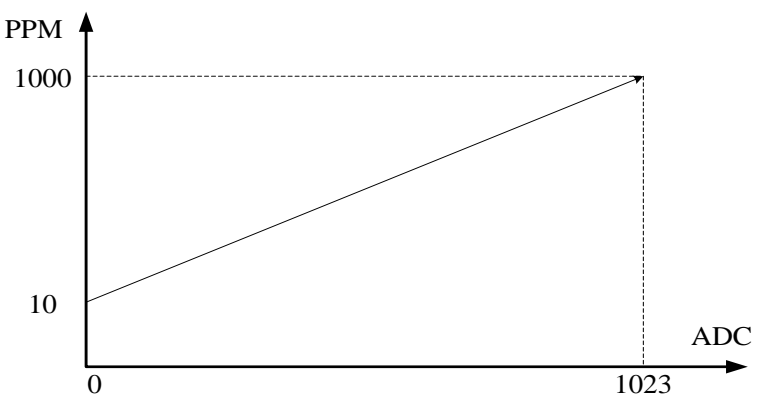

Gambar 10. Kalibrasi Modul MQ-135

Persamaan yang menunjukkan korelasi antara PPM dan ADC adalah sebagai berikut :

$$
P P M=(0.9677 \times A D C)+10
$$

PPM merupakan nilai gas hasil pembacaan dalam satuan part permilion (ppm), sedangkan ADC merupakan nilai pembacaan feature analog to digital modul yang tertanam pada mikrokontroler. Nilai ADC yang digunakan adalah 10 bit dengan resolusi 1024 (0 sampai 1023).

\section{HASIL DAN DISKUSI}

\subsection{Pengujian Konektivitas Bluetooth}

Tabel 3. Jarak Pengukuran Bluetooth

\begin{tabular}{|c|c|c|}
\hline No. & Jarak $(\mathrm{m})$ & Status \\
\hline 1 & 10 & Terhubung \\
\hline 2 & 20 & Terhubung \\
\hline 3 & 27 & Terhubung \\
\hline 4 & 28 & Tidak Terhubung \\
\hline 5 & 29 & Tidak Terhubung \\
\hline 6 & 30 & Tidak Terhubung \\
\hline
\end{tabular}




\subsection{Pengujian Sensor MQ-7}

Berikut merupakan grafik pengujian sensor MQ-7 untuk pengujian 50 kali.
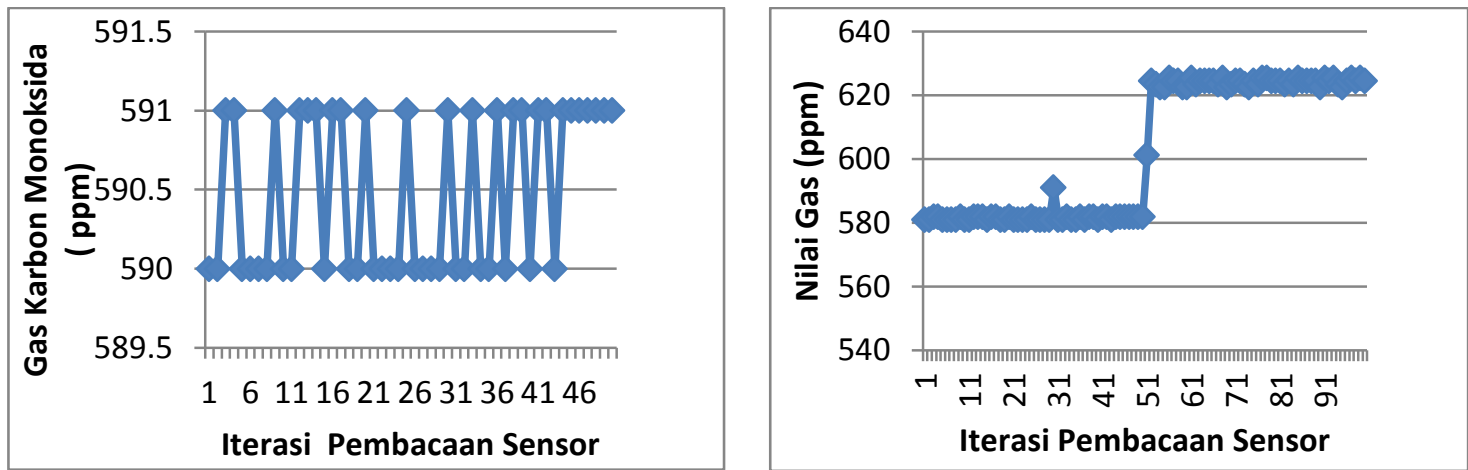

Gambar 11. Hasil Pembacaan Sensor MQ-7

Gambar 11 bagian kiri menunjukkan grafik pembacaan nilai gas karbon monoksida dengan sampel 50 kali. Terlihat bahwa nilai gas karbon monoksida terbaca pada rentang nilai antara $590 \mathrm{ppm}$ sampai dengan 591 ppm pada kondisi normal, sedangkan pada gambar bagian kanan menunjukkan pengujian saat mulai pembacaan adanya gas karbon moniksida.

\subsection{Pengujian Sensor MQ-135}
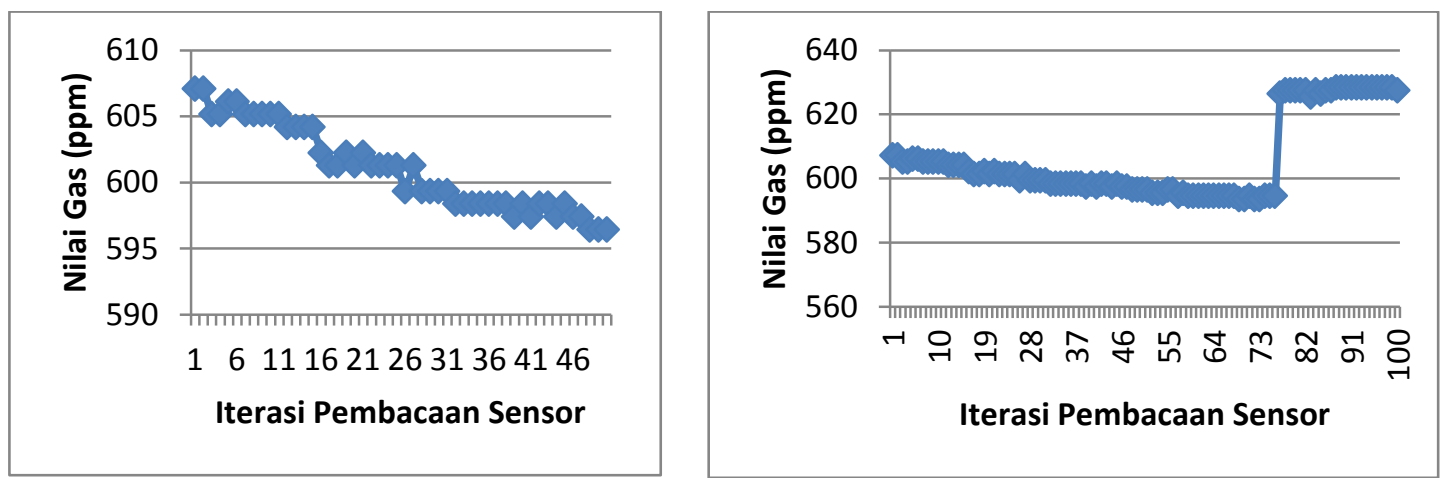

Gambar 12. Hasil Pembacaan Sensor MQ-135

Gambar 12 bagian kiri menunjukkan grafik pembacaan nilai gas MQ-7 dengan sampel 50 kali. Terlihat bahwa nilai gas amonia terbaca pada rentang nilai antara 590 ppm sampai dengan 607 ppm pada kondisi normal, sedangkan pada bagian kanan menunjukkan pengujian saat mulai pembacaan adanya gas pada level ppm di atas 620 .

\subsection{Pengujian Sistem}

Skenario pengujian sistem dilakukan kontrol robot arah maju, mundur, maju belok kanan, maju belok kiri, mundur belok kiri, dan mundur belok kanan. Pada pengujian arah gerak, robot telah bergerak sesuai perintah dengan ketepatan 100\%. Selain itu juga dilakukan skenario pengujian pembacaan sensor pada robot untuk mendeteksi kondisi lingkungan dari gas. Hal pertama yang dilakukan adalah pembacaan sensor pada robot di lingkungan udara bersih untuk didapatkan kondisi aman dari hasil pembacaan. Selanjutnya dilakukan pembacaan pada kondisi udara tercemar untuk kondisi bahaya. Skenario kondisi tercemar dibuat dengan pemberian gas karbon monoksida di daerah sensor gas pada robot melalui pembakaran sampah dan nyala korek 
api. Berdasarkan hasil pengujian pengukuran melalui metode fuzzy yang tertanam pada robot, sistem tersebut sudah bekerja dengan baik.
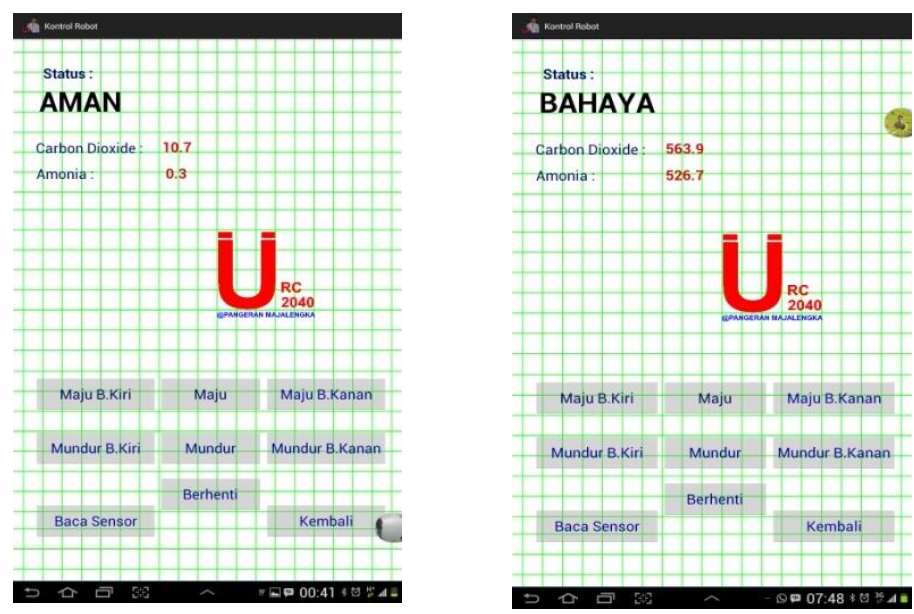

Gambar 13. Pengujian Pembacaan Sensor pada Robot

\section{KESIMPULAN}

Berdasarkan hasil pengujian sistem keseluruhan dapat disimpulkan beberapa poin sebagai berikut :

1. Pada pengujian pergerakan arah robot secara wireless, diperoleh akurasi ketepatan pergerakan arah sebesar $100 \%$.

2. Jarak jangkauan kontrol wireless melalui bluetooth dapat bekerja hingga jarak 27 meter pada kondisi NLOS.

3. Pengujian ketepatan metoda logika fuzzy pada pembacaan kondisi dengan data masukan sensor telah bekerja sesuai dengan yang diharapkan.

\section{DAFTAR PUSTAKA}

[1] Anggraeni , Nur Ika Setyowati. 2009. Pengaruh Lama Paparan Asap Knalpot Dengan Kadar Co 1800 Ppm Terhadap Gambaran Histopatologi Jantung Pada Tikus Wistar. Semarang. Universitas Diponegoro.

[2] SNI 19-0232-2005. Nilai Ambang Batas (NAB) zat kimia di udara tempat kerja. Badan Standardisasi Nasional.

[3] Syahid. 2012. Rancang Bangun Robot Beroda Berbasis Android Menggunakan Komunikasi USB. JTET ISSN : 2252-4908 Vol. 1 No. 2 Agustus 2012 : 33-42. Politeknik Negeri Semarang.

[4] Zadeh, L. A. 1976. A fuzzy-algorithmic approach to the definition of complex or imprecise concepts. Intl. J. Man-Machine Studies, vol. 8, no. 3, pp. 249-291.

[5] Suyanto. 2007. Artificial Intelegent. Bandung : Informatika Bandung.

[6] Sunarya, Unang.2014. Monitoring Robot Pemantau Kelembaban Tanah Tanaman Rumah Kaca Berbasis Mikrokontroler. Seminar Nasional Teknologi Terapan Universitas Gadjah Mada. Yogyakarta.

[7] http://mcuoneclipse.com/2013/06/19/using-the-hc-06-bluetooth-module. [online] (diakses Minggu, 5 Oktober 2014). 
[8] Rasjid, Fadjar Efendy. 2015. Android Sistem Operasi pada Smartphone. Artikel [online] http://www.ubaya.ac.id/ubaya/articles_detail/7/android--sistem-operasi-padasmartphone.html (diakses 20 Mei 2015).

[9] http://www.hwsensor.com. Technical Data Mq-7 Gas Sensor. Hanwei Electronics Co . [online] (diakses Rabu, 20 Mei 2015).

[10] Artikel. MQ135 Semiconductor Sensor for Air Quality Control. 